\title{
Modeling of Mechanical Properties and Morphological Analysis of Glass Fiber Nylon 6 Composite
}

\author{
Piyush P. Gohil ${ }^{1, a}$ \\ ${ }^{1}$ Faculty of Technology and \\ Engineering, \\ The Maharaja Sayajirao University \\ of Baroda, \\ Vadodara - 390 001, Gujarat, India. \\ apush4679@yahoo.com
}

\author{
Jitendra M. Mistry ${ }^{2, b}$ \\ ${ }^{2}$ Sardar Vallabhbhai Patel Institute \\ of Technology, \\ Vasad - 388306, Gujarat, India. \\ ${ }^{2}$ Research Scholar, \\ CHARUSAT, Changa - 388 421, \\ Gujarat, India. \\ b jitumistry190177@gmail.com
}

\author{
Vijay P. Chaudhary ${ }^{3, c}$ \\ ${ }^{3}$ Faculty of Technology and \\ Engineering, \\ CHARUSAT, Changa - 388 421, \\ Gujarat, India. \\ cvijaychaudhary.me@charusat.ac.in
}

\begin{abstract}
The polymer matrix composite material has higher structural efficiency at lower weights as compared to metallic structures, so that they are found in aircraft, space shuttle, automobile and many more industrial applications. In present work, the glass fibers were $15 \%, 30 \%$ and $40 \%$ reinforced by weight in nylon 6 matrix materials for characterisation of mechanical properties. The specimens were fabricated by injection molding as per ASTM. The mechanical properties of glass fiber nylon 6 composites were improved remarkably by adding the glass fiber percentage. The curve fitting technique was used to develop the model for mechanical properties; the developed models are useful to predict the mechanical properties. A perceptible saving of time can be achieved using these models for different combinations of fiber and matrix material. The fiber matrix morphology of the developed composite was examined using scanning electron microscope (SEM).
\end{abstract}

Keywords- Glass fiber; nylon 6; polymer matrix composite; modeling;morphological analysis

\section{INTRODUCTION}

In recent years, polymer matrix composite are gaining more and more utility in aircraft industry, space shuttle, marine parts, automotive components, medical devices, sporting goods and commercial application because they offer advantages such as high specific strength, low weight, low cost, corrosion resistance, wear resistance etc.[1, 2]. A composite is a structural material that consists of two or more elements with considerably different chemical properties that remain separate on macroscopic level in finished component.

M. G. Bader and J. F. Collins have analysed the mechanical properties by varying the volume fraction of glass fiber in nylon 6 [3]. The nylon 6 and maleated ethylene-propylene rubber with glass fibers have found improvement in mechanical properties [4]. P. Davies and D. R. Moore have investigated delamination property of glassfibre-reinforced nylon-66 composites [5]. S. Y. Fu el al. have also studied the effect of short glass and carbon fibers reinforced in polypropylene composite on tensile properties [6]. The mechanical property is improved by adding the glass fiber in various types of matrix $[7,8]$. Glass fibers reinforced composite are the mainstay of PMCs because of their high strength and low cost [9, 10]. When glass fiber combined with nylon 6 , form a fiber based composite with high strength, good dimensional stability and better toughness $[11,12]$. In present work, the tensile property, flexural property, izod impact strength and specific gravity of short, randomly oriented glass fiber reinforced in nylon 6 were investigated. Here an attempt was made to develop the mathematical model for mechanical properties of composite. The bonding between the fiber and matrix, pull out and orientation of fiber were examined by Scanning Electron Microscope (SEM).

\section{EXPERIMENTAL METHODOLOGY}

The methods and instruments used for fabrication and measurement are briefly discussed below.

\section{A. Specimen Preparation}

The process parameters maintained were injection pressure $55 \mathrm{~kg} / \mathrm{cm}^{2}$, injection time $25 \mathrm{sec}$, cooling time 25sec. and screw rpm 60 to fabricate specimens through injection molding machine. Specimens used for testing of mechanical properties as per ASTM are shown in Figure 1. The different temperatures maintained for predefined compositions in different stages during the molding process are as shown in Table 1 . In injection molding machine, the stage 1 is near to hopper side, followed by stages 2 and 3 and stage 4 is nearer to molding die side.

\section{B. Instruments and Methodology}

An electronic Universal Testing Machine, instron 5500 $\mathrm{R}$, was used to measure the tensile testing as per ASTM D638 and flexural testing as per ASTM D790 under three point bending of composite at room temperature. Izod impact strength was determined as per ASTM D256 and specific gravity as per ASTM D792. 


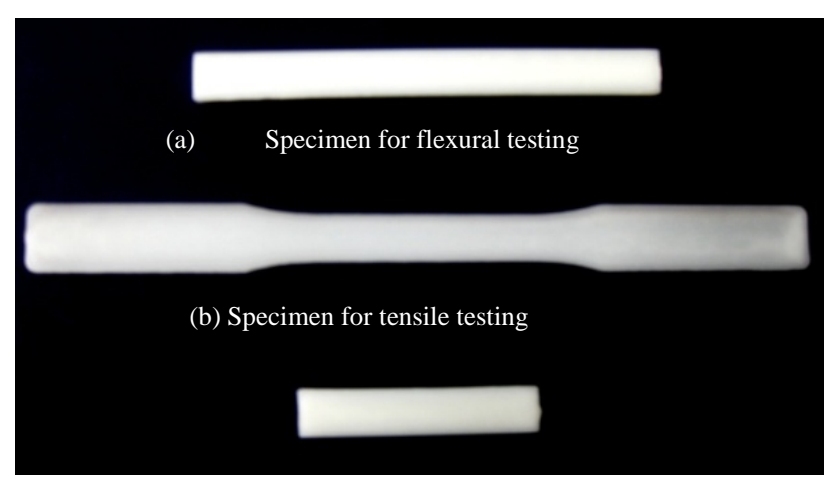

(c) Specimen for izod impact and specific gravity testing

Figure 1 Specimen for (a) flexural testing (b) tensile testing (c) izod impact and specific gravity testing

TABLE 1 TEMPERATURES SELECTED FOR INJECTION MOLDING PROCESS

\begin{tabular}{ccccc}
\hline \multirow{2}{*}{ Material } & \multicolumn{4}{c}{ Temperature $\left[{ }^{0} \mathrm{C}\right]$} \\
\cline { 2 - 5 } & Stage 1 & Stage 2 & Stage 3 & Stage 4 \\
\hline Nylon 6 & 200 & 210 & 225 & 230 \\
Nylon 6 / 15 wt\% GF & 205 & 215 & 230 & 240 \\
Nylon 6 / 30 wt\% GF & 205 & 215 & 230 & 240 \\
Nylon 6 / 40 wt\% GF & 210 & 235 & 250 & 260 \\
\hline
\end{tabular}

\section{RESULT AND DISCUSSION}

Composite is not an isotropic material, so it has different mechanical properties in different directions [13]. Seven specimens tested as per ASTM for mechanical characterisation and the mean value was considered for study of mechanical property. The percentage value in the square bracket of Table 2 shows that percentage rise of respective properties as compared with pure nylon 6 .

\section{A. Tensile Properties}

The value of tensile properties was improved with glass fiber percentage, so it was significant to develop suitable mathematical relation in terms of fiber weight fraction. For that, the value of co efficient of correlation $\left[\mathrm{R}^{2}\right]$ was calculated for different mathematical relation like; linear, polynomial with order 2 , polynomial with order 3 and exponential. The value of $\mathrm{R}^{2}=1$ was obtained in $3^{\text {rd }}$ order polynomial type regression, which is most preferable for the value shown in Table 2 . It means that, the tensile behavior of composites follows $3^{\text {rd }}$ order polynomial regression, so the Figure 2 and 3 are drawn using $3^{\text {rd }}$ order polynomial regression.

The mathematical model developed according to $3^{\text {rd }}$ order polynomial regression between tensile strength $\left(\sigma_{t}\right)$ versus fiber percentage $\left(\Phi_{f}\right)$ and modulus of elasticity $\left(E_{c}\right)$ versus fiber percentage $\left(\Phi_{f}\right)$ is expressed in equations (1) and (2) respectively.

$\sigma_{t}=\left(-0.0025 \mathrm{x}^{3}+0.1167 \mathrm{x}^{2}+1.606 \mathrm{x}+56.98\right) \Phi_{f}$
$E_{c}=\left(-6 \mathrm{E}-05 \mathrm{x}^{3}+0.0038 \mathrm{x}^{2}+0.0223 \mathrm{x}+1.45\right) \Phi_{f}$

TABLE 2 TENSILE PROPERTIES, FLEXURAL PROPERTIES, IZOD IMPACT STRENGTH AND SPECIFIC GRAVITY OF NYLON 6/ GF COMPOSITE

\begin{tabular}{|c|c|c|c|c|c|}
\hline \multirow{2}{*}{$\begin{array}{l}\text { Sr. } \\
\text { No. }\end{array}$} & \multirow{2}{*}{$\begin{array}{l}\text { Properties } \\
\text { of Material }\end{array}$} & \multicolumn{4}{|c|}{ Sample Specimens } \\
\hline & & Nylon 6 & $\begin{array}{c}\text { Nylon 6/ } \\
15 \text { wt \% GF }\end{array}$ & $\begin{array}{c}\text { Nylon 6/ } \\
30 \text { wt \% GF }\end{array}$ & $\begin{array}{c}\text { Nylon 6/ } \\
40 \text { wt \% GF }\end{array}$ \\
\hline 1 & Tensile Strength [MPa] & 56.98 & $99.52[75 \%]$ & $144.62[154 \%]$ & $151.44[165 \%]$ \\
\hline 2 & Modulus of Elasticity [GPa] & 1.45 & $2.43[68 \%]$ & 3.89 [168\%] & $4.53[212 \%]$ \\
\hline 3 & Flexural Strength [MPa] & 85.85 & $141.46[65 \%]$ & 207.09 [141\%] & $224.13[161 \%]$ \\
\hline 4 & Flexural Modulus [GPa] & 2.15 & $3.76[75 \%]$ & $6.78[214 \%]$ & 8.29 [284\%] \\
\hline 5 & Izod Imp. Str. [Kg.Cm/cm] & 3.62 & $4.82[33 \%]$ & 8.38 [131\%] & $10.02[176 \%]$ \\
\hline 6 & Specific Gravity [Unit less] & 1.14 & $1.21[06 \%]$ & $1.348[18 \%]$ & $1.44[26 \%]$ \\
\hline
\end{tabular}




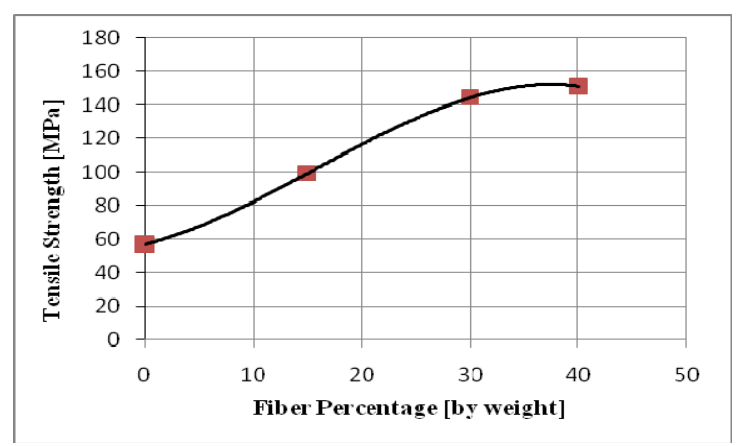

Figure 2 Relationship between tensile strength and fiber percentage

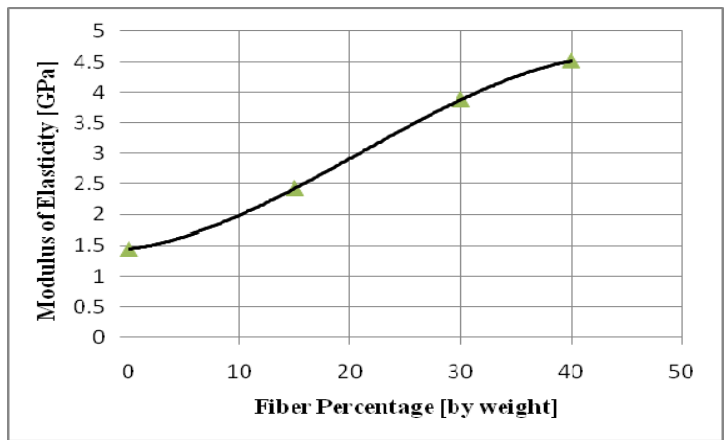

Figure 3 Relationship between modulus of elasticity and fiber percentage

\section{B. Flexural Properties.}

For the flexural property the value of $\mathrm{R}^{2}=1$ observed in $3^{\text {rd }}$ order polynomial type regression. So the Figures 4 and 5 is drawn using $3^{\text {rd }}$ order polynomial regression model. The relationship between flexural strength $\left(\sigma_{f}\right)$ versus fiber percentage $\left(\Phi_{f}\right)$ and flexural modulus $\left(E_{f}\right)$ versus fiber percentage $\left(\Phi_{f}\right)$ demonstrated according to $3^{\text {rd }}$ order polynomial regression are shown in equations (3) and (4) respectively.

$$
\begin{aligned}
& \sigma_{f}=\left(-0.0032 \mathrm{x}^{3}+0.1675 \mathrm{x}^{2}+1.9207 \mathrm{x}+85.85\right) \Phi_{f} \\
& E_{f}=\left(-0.0001 \mathrm{x}^{3}+0.009 \mathrm{x}^{2}+0.0024 \mathrm{x}+2.15\right) \Phi_{f}
\end{aligned}
$$

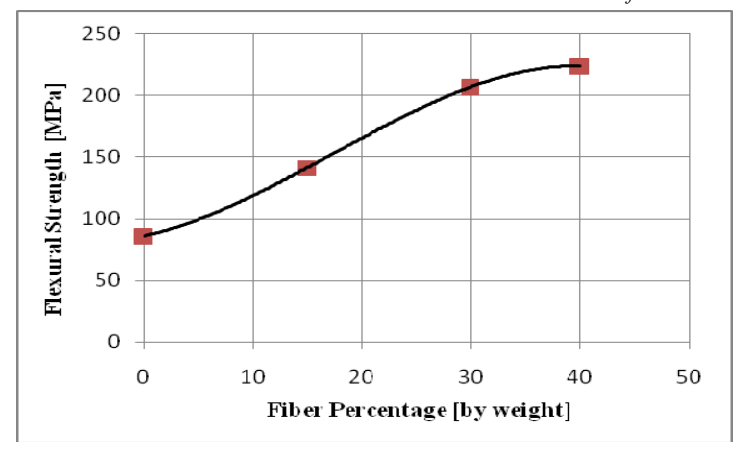

Figure 4 Relationship between flexural strength and fiber percentage

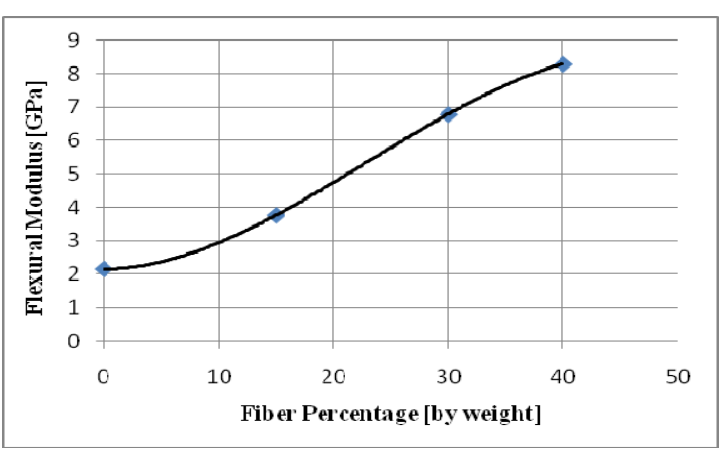

Figure 5 Relationship between flexural modulus and fiber percentage

\section{Izod Impact Strength}

For the izod impact strength and specific gravity, the value of $\mathrm{R}^{2}=1$ observed in $3^{\text {rd }}$ order polynomial type regression. So the Figure 6 and 7 are also demonstrated using $3^{\text {rd }}$ order polynomial regression. The mathematical model shows the relationship between izod impact strength $\left(\sigma_{I}\right)$ versus fiber percentage $\left(\Phi_{f}\right)$ and specific gravity $(S)$ versus fiber percentage $\left(\Phi_{f}\right)$ is illustrated in equations (5) and (6) respectively.

$$
\begin{aligned}
& \sigma_{I}=\left(-0.0002 \mathrm{x}^{3}+0.0144 \mathrm{x}^{2}-0.0907 \mathrm{x}+3.62\right) \Phi_{f} \\
& S=\left(-2 \mathrm{E}-06 \mathrm{x}^{3}+0.0002 \mathrm{x}^{2}+0.0018 \mathrm{x}+1.14\right) \Phi_{f}
\end{aligned}
$$

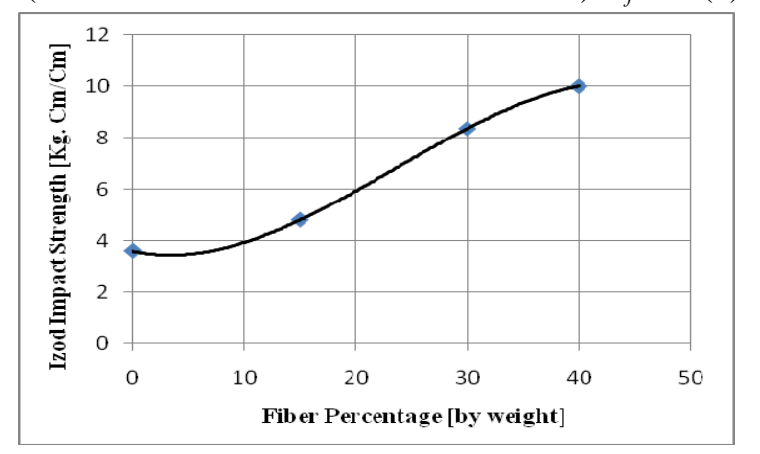

Figure 6 Relationship between izod impact strength and fiber percentage

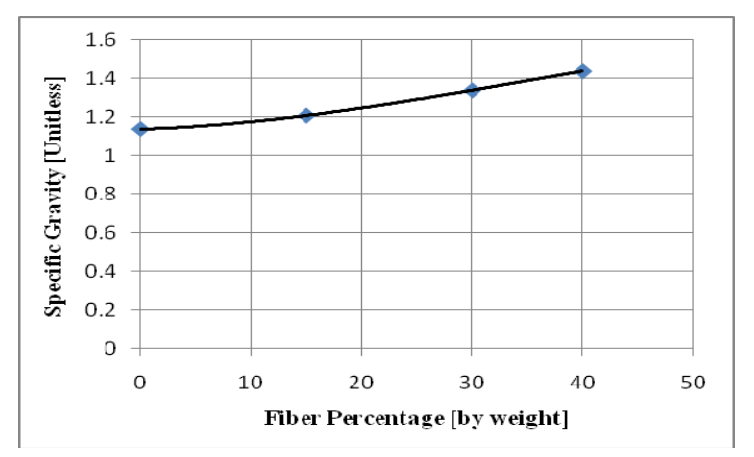

Figure 7 Relationship between specific gravity and fiber percentage

The properties of composites are the result of combined behavior of fiber, matrix and fiber/matrix interface. When glass fiber \% increased in nylon 6 matrix, the strength was increased by considerable amount. It shows compatibility and adequate interfacial bonding strength between glass fiber and nylon 6 materials. A glass fiber allows a very 
large amount of applied load to be transferred through the nylon 6 in composite. Good interfacial bonding between matrix and reinforcement shows that the load carrying capacity are increased with increase of glass fiber percentage [14]. Wettability is very important in PMCs, because liquid matrix must penetrate and wet the fiber tows. This intimate contact between the glass fiber and nylon 6 matrix requires that the latter in liquid form must wet the former, resulting the mechanical property improvement.

\section{MORPHOLOGICAL ANALYSIS}

The composite with $15 \%$, $30 \%$ and $40 \%$ of glass fiber in nylon 6 with different magnification and at various

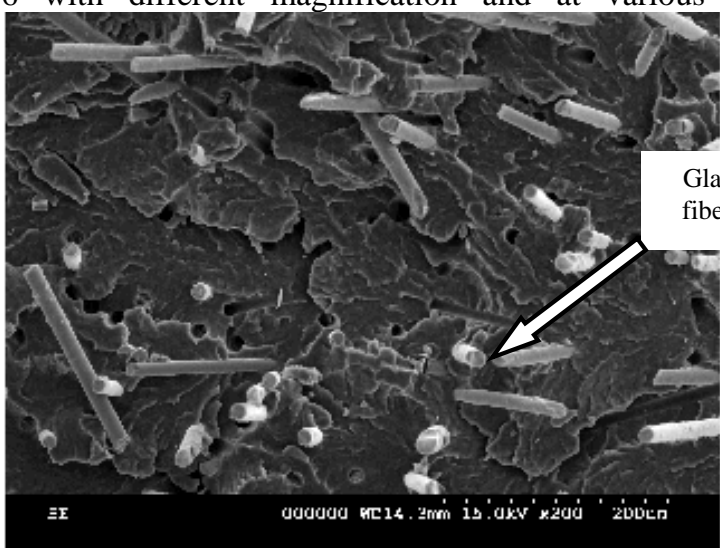

Figure 8 SEM micrograph of Nylon 6/15 wt \% GF
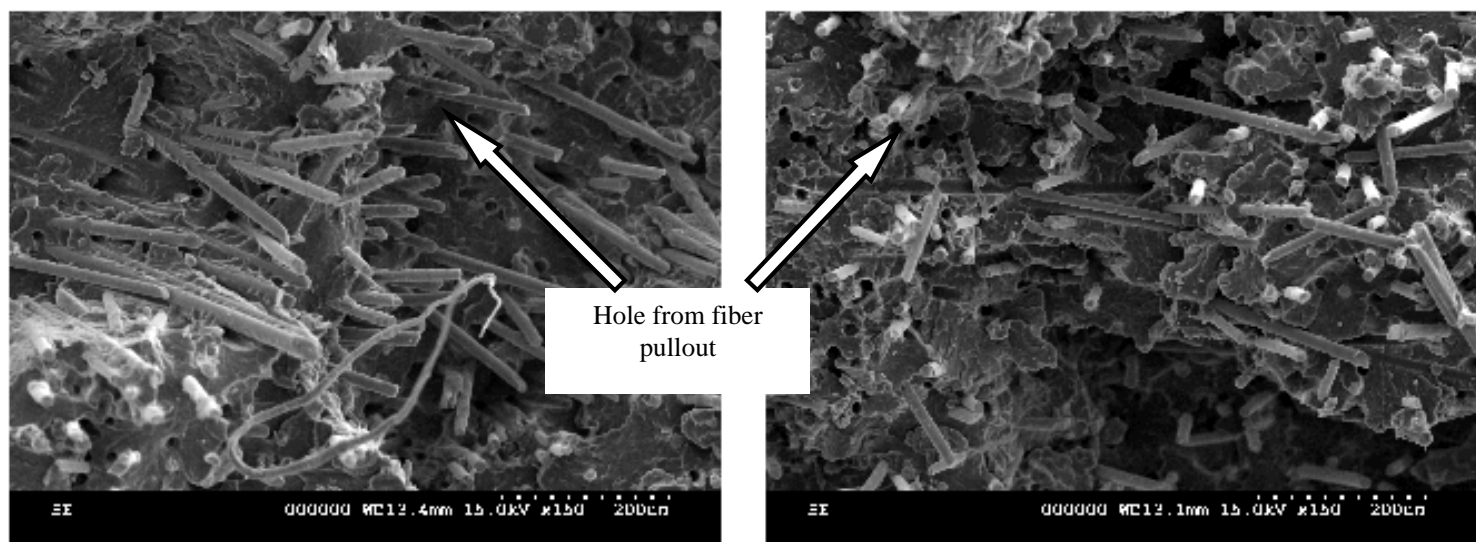

Figure 9 SEM micrograph of Nylon 6/30 wt \% GF
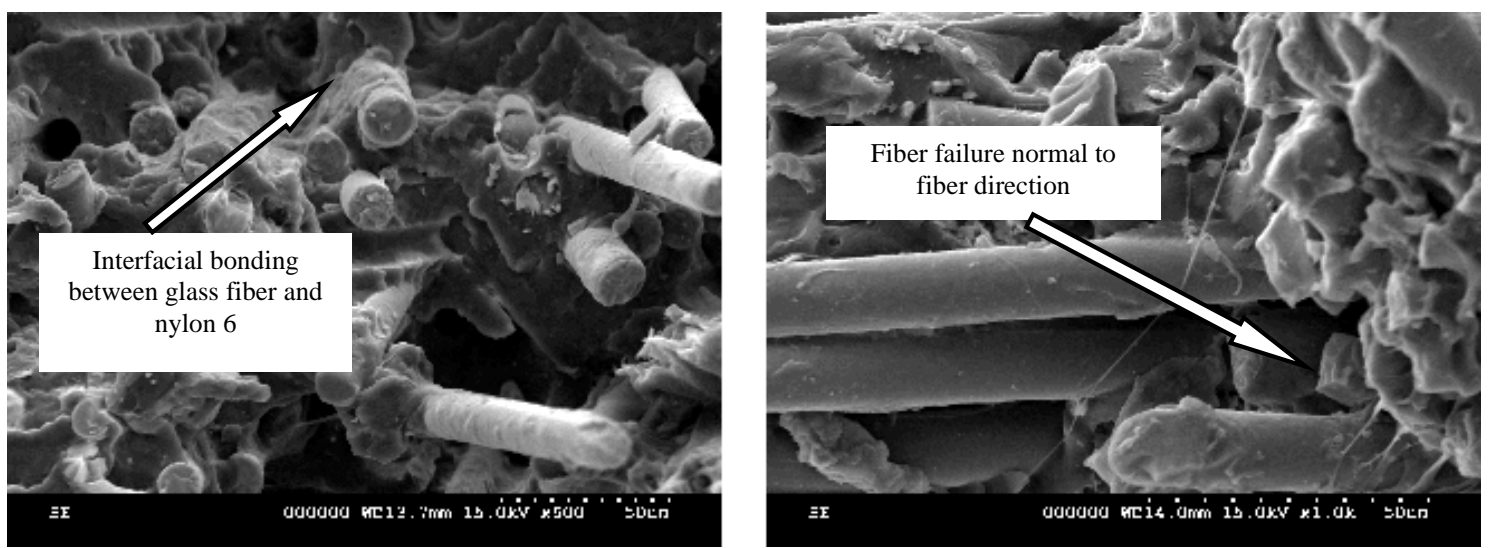

Figure 10 SEM micrograph of Nylon 6/40 wt \% GF

locations are shown in Figures 8, 9 and 10 respectively. It has been observed that glass fibers are randomly oriented testing. Some of the glass fibers are found to be pulled out which might have occurred because of less wettability and poor bonding between them. The failure mode was observed as comparatively more cleavage type, which shows the presence of large percentage of glass fiber as compared to have in case of $15 \%$ and $30 \%$ fibers in the matrix. The failure mode was found to be shifted from ductile to a combination of ductile and brittle with increase of percentage of glass fiber with relatively higher percentage of brittle mode.

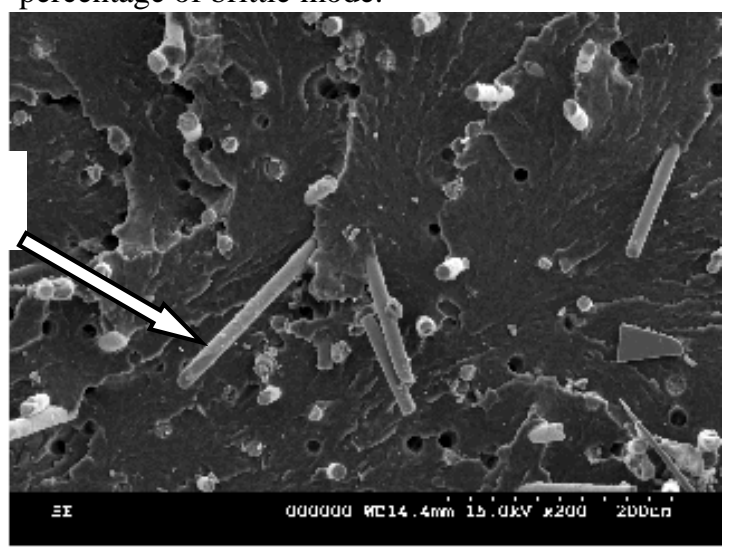

\section{.}




\section{CONCLUSION}

Following conclusions are drawn from present experimental investigation.

- The tensile strength and modulus of elasticity increased $165 \%$ and $212 \%$ respectively with $40 \%$ of glass fiber in nylon 6 . The flexural strength and flexural modulus were $161 \%$ and $283 \%$ improved respectively by adding glass fiber up to $40 \%$ in nylon 6 matrix. Izod impact strength and specific gravity increased up to $176 \%$ and $26 \%$ with $40 \%$ of glass fiber reinforced in nylon 6 . Which shows that very good interfacial bonding and wettability between glass fiber and nylon 6.

- The developed model of mechanical properties follow the behavior of $3^{\text {rd }}$ order polynomial type regression in glass fiber nylon 6 composite.

- $\quad$ The developed models for mechanical properties of glass fiber reinforced nylon 6 composite are convincingly accurate for prediction. A perceptible saving of time can be achieved using these models for various combinations of fiber and matrix as per the structural requirement of particular industrial product to be replaced with light weight material.

\section{ABBREVIATION AND NOMENCLATURE}

PMCs Polymer Matrix Composite

GF Glass Fiber

$\mathrm{R}^{2} \quad$ Co efficient of Correlation

$\sigma_{t} \quad$ Tensile Strength [MPa]

$E_{c} \quad$ Modulus of Elasticity [GPa]

$\sigma_{f} \quad$ Flexural Strength [MPa]

$\mathrm{E}_{\mathrm{F}} \quad$ Flexural Modulus [GPa]
$\sigma_{I} \quad$ Izod Impact Strength [Kg. $\left.\mathrm{Cm} / \mathrm{cm}\right]$

$S \quad$ Specific Gravity [Unit less]

$\Phi_{f} \quad$ Fiber Weight Percentage

\section{REFERENCES}

[1] R. F. Gibson, Principle of Composite Material mechanics, McGraw Hill series in mechanical engineering, New York international edition (1994).

[2] S. Nagae, K. Nakamae, International Journal of Adhesion and Adhesives, Vol. 22 (2002), p. 139

[3] M.G. Bader, J.F. Collins, Fibre Science and Technology, Vol. 18 (1983), p. 217

[4] D.M. Laura, H. Keskkula, J.W. Barlow, D.R. Paul, Polymer, Vol. 43 (2002), p. 4673

[5] P. Davies, D.R. Moore, Composites Science and Technology, Vol. 38 (1990), p. 211

[6] S.Y. Fu, B. Lauke, E. Mäder, C.Y. Yue, X. Hu, Composites Part A: Applied Science and Manufacturing, Vol. 31 (2000), p. 1117

[7] M.P. Weifeng Chen, Min Xiao, Shuanjin Wang, Lishi Wen, and Yuezhong Meng, Journal of Reinforced Plastics and Composites, Vol. 29 (May 2010), p. 1545

[8] G. Ren, P.J. Hogg, D.H. Woolstencraft, Advances in Applied Ceramics, Vol. 111 (2012), p. 113

[9] S. Hreglich, F. Cioffi, Advances in Applied Ceramics, Vol. 108 (2009), p. 22

[10] E. Bernardo, L. Esposito, E. Rambaldi, A. Tucci, Advances in Applied Ceramics, Vol. 108 (2009), p. 2

[11] A. Pegoretti, M. Fidanza, C. Migliaresi, A.T. DiBenedetto, Composites Part A: Applied Science and Manufacturing, Vol. 29 (1998), p. 283

[12] A. Güllü, A. Özdemir, E. Özdemir, Materials \& Design, Vol. 27 (2006), p. 316

[13] P.P. Gohil, A.A. Shaikh, Materials \& Design, Vol. 51 (2013), p. 105

[14] J.-Z. Liang, Journal of Thermoplastic Composite Materials, Vol. 18 (2005), p. 407 